\title{
Effects of miglitol in platelet-derived microparticle, adiponectin, and selectin level in patients with type 2 diabetes mellitus
}

This article was published in the following Dove Press journal:

International Journal of General Medicine

19 July 2011

Number of times this article has been viewed

\section{Shosaku Nomura \\ Seitaro Omoto ${ }^{2}$ \\ Takashi Yokoi' \\ Shinya Fujita' \\ Ryotaro Ozasa' \\ Noritaka Eguchi ${ }^{3}$ \\ Akira Shouzu ${ }^{3}$}

'First Department of Internal Medicine, Kansai Medical University, ${ }^{2}$ Division of Internal Medicine, Korigaoka Yukeikai Hospital, ${ }^{3}$ Division of Internal Medicine, Saiseikai Izuo Hospital, Osaka, Japan
Correspondence: Shosaku Nomura First Department of Internal Medicine, Kansai Medical University, 10-15 Fumizono-cho, Moriguchi, Osaka 570-8507, Japan

$\mathrm{Tel}+8 \mathrm{I} 669939453$

Fax +8I 669921293

Email shosaku-n@mbp.ocn.ne.jp
Background: Platelet-derived microparticles (PDMP), selectins, and adiponectin play an important role in the development of atherosclerosis in diabetes. Miglitol has been shown to have a beneficial effect on postprandial hyperglycemia in diabetic patients. However, its influence on platelet activation markers (PDMP and soluble CD40 ligand [sCD40L]), selectins, and adiponectin in these patients is poorly understood.

Aim: We investigated the effect of miglitol on circulating levels of PDMP, sCD40L, selectins, and adiponectin in patients with type 2 diabetes.

Methods: Miglitol (150 mg/day) was administered for 4 months. Levels of PDMP, sCD40L, soluble P-selectin (sP-selectin), soluble E-selectin (sE-selectin), soluble L-selectin (sL-selectin), and adiponectin were measured by enzyme-linked immunosorbent assay at baseline, and after 1 and 4 months of treatment.

Results: The levels of PDMP, sCD40L, sP-selectin, sE-selectin, and sL-selectin were higher in diabetic patients than in hypertensive patients, while there were no significant differences between hypertensive and hyperlipidemic patients. Before miglitol treatment, the adiponectin level of diabetic patients was lower than that of hypertensive patients. Miglitol therapy significantly decreased the plasma PDMP and sCD40L levels relative to baseline. Miglitol also caused a significant decrease of sP-selectin, sE-selectin, and sL-selectin. On the other hand, miglitol therapy led to a significant increase in adiponectin after 4 months of administration compared with baseline. Furthermore, the reduction of platelet activation markers and selectins during miglitol therapy was significantly greater in the responder (adiponectin-improved) group than the nonresponder group of diabetic patients.

Conclusion: Miglitol has an adiponectin-dependent anti-atherothrombotic effect that may be beneficial for primary prevention of atherothrombosis in patients with type 2 diabetes.

Keywords: platelet activation markers, atherothrombosis, platelet-derived microparticles, PDMP

\section{Introduction}

Diabetic patients develop hypercoagulability and platelet hyperaggregability, ${ }^{1,2}$ along with increased levels of platelet activation markers such as platelet-derived microparticles (PDMP). ${ }^{3}$ Expression of cell adhesion molecules is also increased in diabetes, ${ }^{4}$ and these molecules have been suggested to have a role in the microvascular complication of this disease. P-selectin is an adhesion molecule that is involved in adhesion of platelets to leukocytes or the endothelium. ${ }^{5}$ Serum levels of soluble P-selectin (sP-selectin) are elevated in patients with diabetes. ${ }^{6,7}$ The first step in the process of leukocyte migration into the subendothelial space is the adhesion of circulating 
leukocytes to the endothelium, which may involve adhesion molecules like L-selectin and can eventually lead to vascular complications.

A large volume of epidemiological data indicates that persons with postprandial hyperglycemia have an increased risk of cardiovascular disease. ${ }^{8,9}$ Patients with postprandial hyperglycemia often have accompanying postprandial hyperinsulinemia. However, the postprandial rise in blood glucose itself is now considered to be a risk factor for the progression of atherosclerosis. ${ }^{10,11} \alpha$-Glucosidase inhibitors $(\alpha-\mathrm{GI})$ such as acarbose have shown long-term beneficial and protective effects against atherosclerosis. The Study to Prevent Non-Insulin-Dependent Diabetes Mellitus (STOP-NIDDM) trial demonstrated that treatment with acarbose reduces the onset of diabetes and the incidence of cardiovascular disease and new hypertension in patients with impaired glucose tolerance. ${ }^{12-14}$ A meta-analysis of seven long-term studies has also shown that acarbose prevents myocardial infarction and cardiovascular disease in patients with type 2 diabetes. ${ }^{15}$ These findings suggest that inhibition of postprandial hyperglycemia by $\alpha$-GI may be a promising therapeutic strategy for the prevention of cardiovascular disease in patients with impaired glucose tolerance and/or diabetes.

Miglitol, another $\alpha-G I$, has unique pharmacokinetics. ${ }^{16}$ After oral administration, it is rapidly and completely absorbed, even at a high dose, from the small intestines, ${ }^{16}$ even though other $\alpha$-GIs are scarcely absorbed there. These pharmacokinetics enable early-phase suppression of postprandial glucose elevation with a decrease in the severity of gastrointestinal complications, even at high doses, because absorption of carbohydrates is very low in the lower small intestine where miglitol is concentrated. However, the effects of miglitol on platelet activation markers, selectins, and adiponectin in patients with type 2 diabetes are poorly understood. Therefore, this study was performed to investigate the effects of miglitol on platelet activation markers, selectins, and adiponectin in type 2 diabetic patients.

\section{Methods}

\section{Patients}

The subjects included 72 nondiabetic (37 patients with hypertension and 35 patients with hyperlipidemia) and 38 diabetic patients (Table 1). Between April 2007 and November 2009, patients were selected from among those admitted to our hospital for the treatment of hypertension, hyperlipidemia, and diabetes. The study protocol was approved by our Institutional Review Board, and written informed consent was obtained from each patient prior to starting the trial. A history (within 3 months prior to enrolment) of inflammatory disease, coronary artery disease, or cerebrovascular disease was not permitted. Clinically detectable renal dysfunction (serum creatinine $\geq 2.0 \mathrm{mg} / \mathrm{dL}$ ), hepatic dysfunction (elevated transaminases), infection (fever or elevated white blood cell count), or malignancy (detected by ultrasound or computed tomography) were also not permitted. Ten patients were taking aspirin because of old cerebral infarction or angina pectoris, while 39 patients were using angiotensin II receptor blockers (ARBs), and 24 patients were taking $\mathrm{Ca}$ antagonists for hypertension (Table 1). There were also 27 patients taking statins for hyperlipidemia. The doses of prior drugs such as aspirin, statins, ARBs, and Ca-antagonists were not adjusted during the present study.

\section{Study design}

Miglitol (150 mg/day) was administered for 4 months to randomly selected patients. There were no other changes to drug therapy during the treatment. Clinical and biochemical data were obtained before and after starting acarbose administration.

Table I Baseline characteristics of the study population

\begin{tabular}{|c|c|c|c|}
\hline & Hypertension & Hyperlipidemia & Diabetes \\
\hline Number of patients & 37 & 35 & 38 \\
\hline Gender (male/female) & $21 / 16$ & $18 / 17$ & $20 / 18$ \\
\hline Age, years & $61 \pm 4$ & $62 \pm 7$ & $63 \pm 6$ \\
\hline BMI, kg/m² & $25.2 \pm 3.1$ & $26.6 \pm 4.5$ & $27.6 \pm 4.3$ \\
\hline $\mathrm{TC}, \mathrm{mg} / \mathrm{dL}$ & $|98 \pm 4|$ & $245 \pm 19$ & $235 \pm 32$ \\
\hline $\mathrm{TG}, \mathrm{mg} / \mathrm{dL}$ & $140 \pm 25$ & $242 \pm 43$ & $228 \pm 35$ \\
\hline HDL-C, mg/dL & $51 \pm 11$ & $46 \pm 13$ & $45 \pm 11$ \\
\hline LDL-C, mg/dL & $119 \pm 25$ & $152 \pm 37$ & $143 \pm 40$ \\
\hline HbAlc (\%) & $4.8 \pm 0.5$ & $5.2 \pm 1.3$ & $7.5 \pm 1.4$ \\
\hline \multicolumn{4}{|l|}{ Complications, n (\%) } \\
\hline Angina pectoris & $6(16.2)$ & $3(8.6)$ & $5(\mid 3.2)$ \\
\hline Heart failure & $3(8.1)$ & $2(5.7)$ & $2(5.3)$ \\
\hline Cerebral infarction & I (2.7) & $2(5.7)$ & $3(7.9)$ \\
\hline Hypertension & - & $5(14.3)$ & $7(18.4)$ \\
\hline Hyperlipidemia & $4(10.8)$ & - & $3(7.9)$ \\
\hline Diabetes mellitus & $0(0)$ & $0(0)$ & - \\
\hline \multicolumn{4}{|l|}{ Medications, n (\%) } \\
\hline Aspirin & $3(8.1)$ & I (2.9) & $5(13.2)$ \\
\hline Statins & $5(13.5)$ & $20(57.1)$ & $2(5.3)$ \\
\hline ARBs & $25(67.6)$ & $8(22.9)$ & $6(15.8)$ \\
\hline $\mathrm{Ca}$ antagonists & $18(48.6)$ & $2(5.7)$ & $4(10.5)$ \\
\hline
\end{tabular}

Note: Data are shown as mean \pm standard deviation.

Abbreviations: BMI, body mass index; TC, total cholesterol; TG, triglyceride; HDL-C, high-density lipoprotein cholesterol; LDL-C, low-density lipoprotein cholesterol; HbA Ic, hemoglobin A I c; ARB, angiotensin II receptor blocker. 


\section{Measurement of platelet-derived microparticles}

An enzyme-linked immunosorbent assay (ELISA) kit for the detection of PDMPs ${ }^{17-19}$ was obtained from Jimro Co, Ltd (Tokyo, Japan). Briefly, a blood sample was collected from a peripheral vein into a vacutainer containing EDTA-ACD (ethylenediaminetetraacetic acid-acid citrate dextrose solution) (Nipro Co Ltd, Japan) with a 21-gauge needle to minimize platelet activation. The sample was gently mixed by inverting the tube once or twice and then left at room temperature for 2-3 hours, followed by centrifugation at $8000 \mathrm{~g}$ for 5 minutes at room temperature. Immediately after centrifugation, we collected $200 \mu \mathrm{L}$ of the upper layer of supernatant from a 2-mL sample to avoid contamination and stored each sample at $-40^{\circ} \mathrm{C}$ until analysis. The results of the ELISA performed under the current experimental conditions were reproducible. PDMPs were measured twice, and the mean value was calculated. The kit employed two monoclonal antibodies directed against platelet glycoproteins CD42b and CD42a (glycoprotein Ib and IX). One U/mL of PDMP was defined as 24,000 solubilized platelets/mL in this ELISA.

\section{Measurement of adiponectin, soluble CD40 ligand (sCD40L), sP-selectin, soluble E-selectin (sE-selectin), and soluble L-selectin (sL-selectin)}

Blood samples from patients and controls were collected into tubes containing sodium citrate or tubes without anticoagulant and were allowed to clot at room temperature for a minimum of 1 hour. Serum or citrated plasma was then isolated by centrifugation for 20 minutes at $1000 \mathrm{~g}\left(4^{\circ} \mathrm{C}\right)$ and stored at $-30^{\circ} \mathrm{C}$ until analysis with an adiponectin ELISA kit (Otsuka Pharmaceuticals Co Ltd, Tokyo, Japan). sCD40L, sP-selectin, sE-selectin, and sL-selectin were measured with a monoclonal antibody-based ELISA kit from BioSource International Inc (Camarillo, CA). The recombinant products and standard solutions provided with the kits were used as positive controls in each assay, and procedures were done according to the manufacturers' instructions.

\section{Statistics}

Data are expressed as the mean \pm standard deviation and were analyzed by two-factor analysis of variance (ANOVA) for repeated measures, as it was appropriate. Between-group comparisons were made with the Bonferroni test, and withingroup differences were assessed with Student's paired $t$-test. The level of significance was $P<0.05$.

\section{Results}

When baseline values before treatment were compared among the three patient groups, no significant differences were noted for any of the parameters (Table 1).

The levels of PDMP, sCD40L, sE-selectin, sP-selectin, and sL-selectin were higher in diabetic patients than in hypertensive patients (Table 2). However, there were no significant differences between the hypertensive and hyperlipidemic patients. Before miglitol treatment, adiponectin levels were lower in the diabetic patients than the hypertensive patients (Table 2). There were no significant differences between the hypertensive and hyperlipidemic patients with respect to PDMP, sCD40L, sP-selectin, sE-selectin, and sL-selectin, although they showed a slight difference for adiponectin (Table 2).

Miglitol therapy significantly decreased the plasma PDMP level relative to baseline (before vs 1 month vs 4 months; $21.2 \pm 7.6$ vs $18.2 \pm 8.5$ vs $15.4 \pm 6.5 \mathrm{U} / \mathrm{mL}$; 1 month, not significant [NS]; 4 months, $P<0.01$ ) (Figure 1). Miglitol also caused a significant decrease in $\mathrm{SCD}^{2} \mathrm{LL}$ (before vs 1 month vs 4 months; $3.1 \pm 1.2$ vs $2.8 \pm 1.1$ vs $2.3 \pm 0.9 \mathrm{ng} / \mathrm{mL} ; 1$ month, NS; 4 months, $P<0.05)$, sP-selectin (before vs 1 month vs 4 months; $213 \pm 98$ vs $194 \pm 73$ vs $162 \pm 81 \mathrm{ng} / \mathrm{mL} ; 1$ month, NS, 4 months; $P<0.05$ ), sE-selectin (before vs 1 month vs 4 months; $696 \pm 141$ vs $688 \pm 235$ vs $579 \pm 128 \mathrm{ng} / \mathrm{mL} ; 1$ month, NS; 4 months, $P<0.05$ ), and sL-selectin (before vs 1 month vs 4 months; $631 \pm 195$ vs $620 \pm 139$ vs $562 \pm 124 \mathrm{ng} / \mathrm{mL}$; 1 month, NS; 4 months, $P<0.05$ ) (Figure 1). On the other hand, miglitol therapy led to a significant increase in adiponectin levels after 4 months compared with baseline (before vs 1 month vs 4 months; $2.41 \pm 1.22$ vs $2.82 \pm 1.34$ vs $4.63 \pm 1.85 \mu \mathrm{g} / \mathrm{mL} ; 1$ month, NS; 4 months, $P<0.01)$ (Figure 1).

Table 2 Levels of PDMP, sCD40 L, adiponectin, and selectins in patients with hypertension, hyperlipidemia, or type 2 diabetes

\begin{tabular}{lccc}
\hline & Hypertension & Hyperlipidemia & Diabetes \\
\hline PDMP, U/mL & $13.9 \pm 4.6$ & $16.4 \pm 5.9^{\mathrm{a}}$ & $21.2 \pm 7.6^{\mathrm{b}}$ \\
$\mathrm{sCD} 40 \mathrm{~L}, \mathrm{ng} / \mathrm{mL}$ & $1.8 \pm 0.7$ & $2.2 \pm 1.0^{\mathrm{a}}$ & $3.1 \pm 1.2^{\mathrm{c}}$ \\
sP-selectin, ng/mL & $136 \pm 74$ & $155 \pm 83^{\mathrm{a}}$ & $213 \pm 98^{\mathrm{b}}$ \\
$\mathrm{sE}-$ selectin, $\mathrm{ng} / \mathrm{mL}$ & $65 \pm 31$ & $79 \pm 44^{\mathrm{a}}$ & $96 \pm 41^{\mathrm{c}}$ \\
sL-selectin, $\mathrm{ng} / \mathrm{mL}$ & $512 \pm 160$ & $574 \pm 172^{\mathrm{a}}$ & $631 \pm 195^{\mathrm{c}}$ \\
Adiponectin, $\mu \mathrm{g} / \mathrm{mL}$ & $5.32 \pm 0.93$ & $3.84 \pm 1.04^{\mathrm{c}}$ & $2.41 \pm 1.22^{\mathrm{b}}$ \\
\hline
\end{tabular}

Notes: ${ }^{a}$ Not significant; ${ }^{b} P<0.01$; ${ }^{c} P<0.05$; Data are shown as the mean \pm standard deviation.

Abbreviations: PDMP, platelet-derived microparticle; sCD40 L, soluble CD40 ligand; sP-selectin, soluble P-selectin; sE-selectin, soluble E-selectin; sL-selectin, soluble L-selectin. 


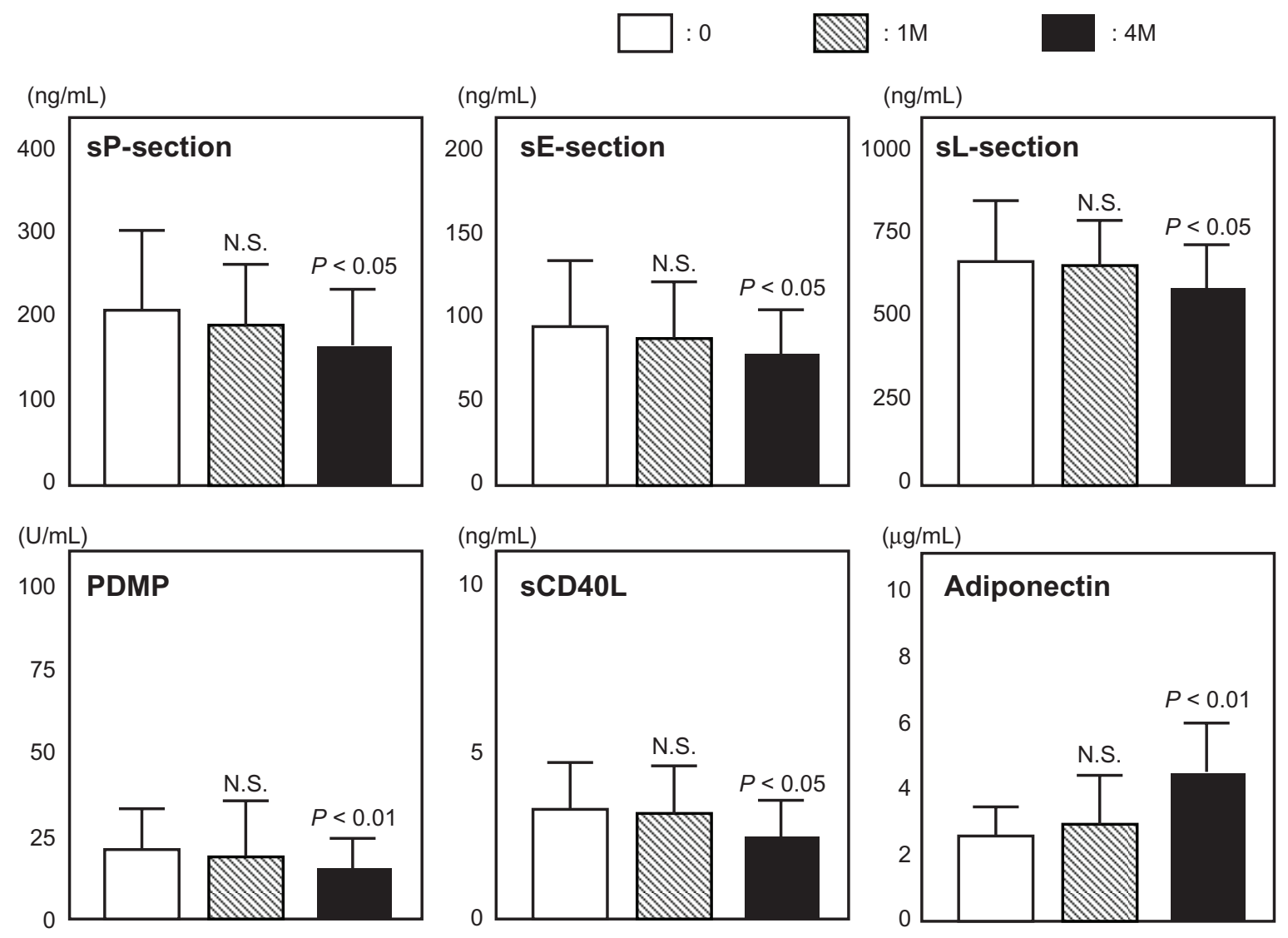

Figure I Changes in PDMP, sCD40L, sP-selectin, sE-selectin, sL-selectin, and adiponectin following administration of miglitol to patients with type 2 diabetes. Bars show the mean \pm standard deviation. $P$-values are for comparison with each baseline parameter (before vs I month or 4 months). 0 denotes before; $M$ denotes month (after).

Abbreviations: N.S., not significant; PDMP, platelet-derived microparticle; sCD40L, soluble CD40 ligand; sP-selectin, soluble P-selectin; sE-selectin, soluble E-selectin; sLselectin, soluble L-selectin.

We divided the patients of the diabetes group into two subgroups (responders and nonresponders) according to their adiponectin response to miglitol treatment. Responders were defined as those patients in whom the plasma adiponectin levels increased by one and a half times or more after miglitol treatment as compared with pretreatment levels. The plasma values of PDMP and SCD40L in the two groups are shown in Figure 2. Significant decreases in the plasma PDMP and sCD40L levels were observed in the responder group after miglitol treatment (PDMP before treatment vs after treatment: responder group $22.3 \pm 6.4$ vs $16.8 \pm 6.6 \mathrm{U} / \mathrm{mL}, P<0.01$; nonresponder group $19.4 \pm 5.9$ vs $18.6 \pm 6.3 \mathrm{U} / \mathrm{mL}$, NS, ANOVA; responder group vs nonresponder group $P<0.05$. SCD40L before treatment vs after treatment: responder group $3.4 \pm 1.3$ vs $2.5 \pm 1.2 \mathrm{ng} / \mathrm{mL}, P<0.05$; nonresponder group $3.0 \pm 1.6$ vs $2.7 \pm 1.7 \mathrm{ng} / \mathrm{mL}$, NS, ANOVA; responder vs nonresponder, $P<0.05$ ). The plasma values of selectins in the two groups are also shown in Figure 2. Significant decreases in plasma sP-selectin, sE-selectin, and sL-selectin were observed after miglitol treatment in the responder group (sP-selectin before treatment vs after treatment: responder group $229 \pm 88$ vs $176 \pm 75 \mathrm{ng} / \mathrm{mL}, P<0.01$; nonresponder group: $203 \pm 85$ vs $188 \pm 87 \mathrm{ng} / \mathrm{mL}$, NS, ANOVA; responder group vs nonresponder group $P<0.05$. sE-selectin before treatment vs after treatment: responder group $102 \pm 44$ vs $81 \pm 39 \mathrm{ng} / \mathrm{mL}$, $P<0.05$; nonresponder group $93 \pm 38$ vs $88 \pm 40 \mathrm{ng} / \mathrm{mL}$, NS, ANOVA; responder group vs nonresponder group, $P<0.05$. sL-selectin before treatment vs after treatment: responder group $649 \pm 188$ vs $576 \pm 175 \mathrm{ng} / \mathrm{mL}, P<0.05$; nonresponder group $613 \pm 156$ vs $592 \pm 163 \mathrm{ng} / \mathrm{mL}$, NS, ANOVA; responder group vs nonresponder group $P<0.05$ ).

\section{Discussion}

PDMPs play an important role in the clotting process, so an increase in PDMPs is likely to cause hypercoagulability. ${ }^{20}$ We previously reported that PDMP levels were significantly increased in diabetic patients. ${ }^{21}$ Because PDMPs promote the expression of adhesion molecules by monocytes and endothelial cells, ${ }^{22}$ it seems possible that these microparticles may participate in the development or progression of atherosclerosis in diabetics. Strong antiplatelet drugs such as cilostazol or ticlopidine can inhibit the elevation of PDMP, ${ }^{23-25}$ but the 


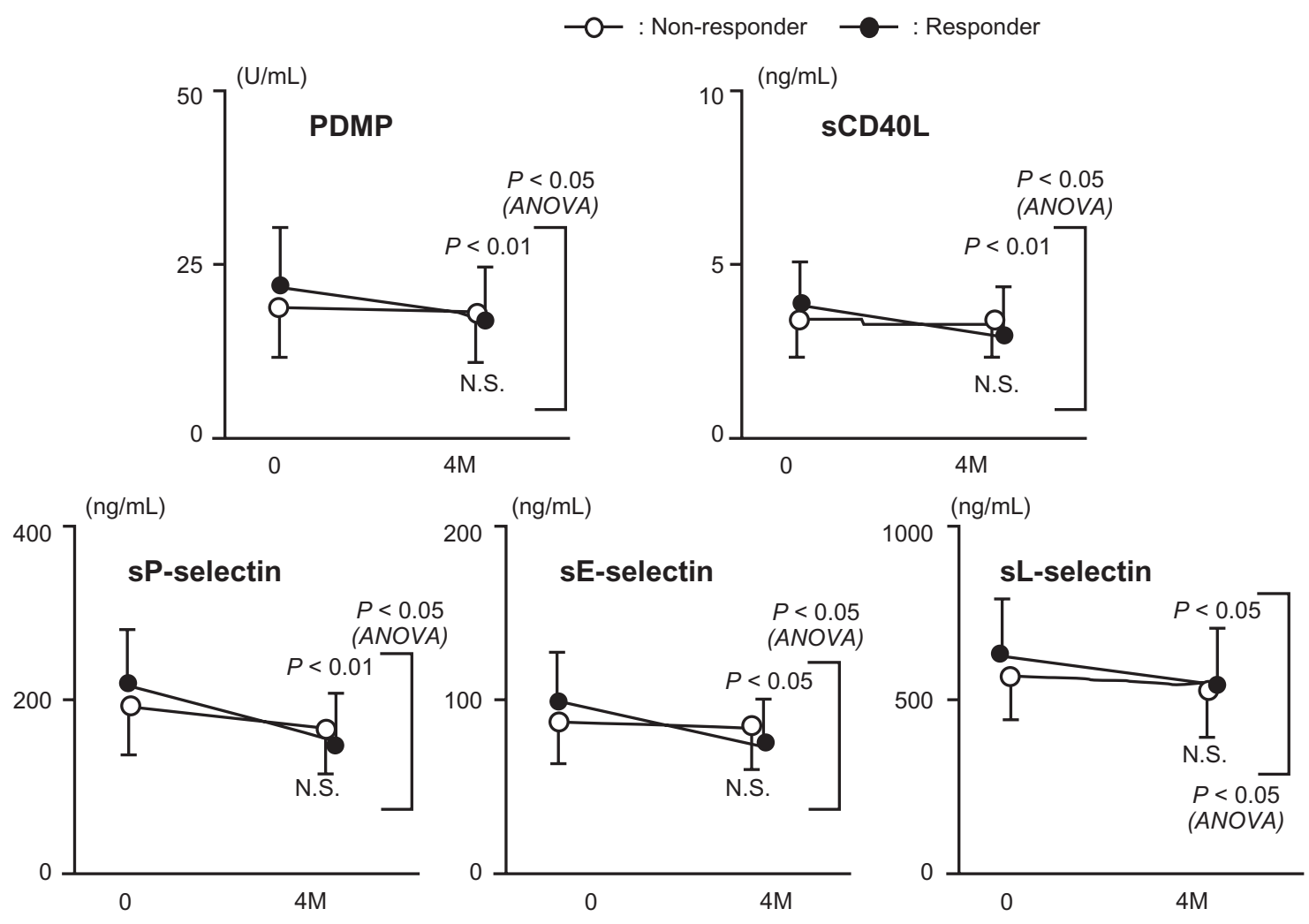

Figure 2 Changes in PDMP, sCD40L, sP-selectin, sE-selectin, and sL-selectin during administration of miglitol to type 2 diabetic patients with or without a significant improvement in adiponectin. Responder: with a significant improvement of adiponectin. Nonresponder: without a significant improvement of adiponectin. Bars show the mean \pm standard deviation. 0 denotes before; $M$ denotes month (after). $P$-values are for comparison with each baseline parameter (before vs 4 months).

Abbreviations: ANOVA, analysis of variance (nonresponder vs responder); N.S., not significant; PDMP, platelet-derived microparticle; sCD40L, soluble CD40 ligand; sPselectin, soluble P-selectin; sE-selectin, soluble E-selectin; sL-selectin, soluble L-selectin.

use of these agents for primary prevention of atherothrombosis is problematic. Thus, a new strategy is needed for diabetic patients who are highly susceptible to atherothrombosis. In the present study, miglitol therapy significantly decreased plasma PDMP levels. Although no direct changes in platelet function were shown, miglitol therapy also improved another platelet activation marker (sCD40L) in our patients with diabetes. Postprandial hyperglycemia may be related to the activation of platelets in diabetic patients. Postprandial hyperglycemia induces oxidative stress via various biochemical pathways, and generation of superoxide occurs, which reacts with nitric oxide (NO) to form peroxynitrite. ${ }^{26}$ The resulting decrease in NO levels and activity could accelerate vascular inflammation and platelet activation by enhancing the expression of various cytokines and growth factors. ${ }^{27}$ Thus, our results indicate that postprandial hyperglycemia causes platelet activation and endothelial dysfunction. Treatment with miglitol significantly reduces body mass index and waist circumference. ${ }^{28,29}$ It has also been reported that miglitol prevents nephropathic complication in type 2 diabetic patients. ${ }^{29}$ Our results could explain one of the mechanisms involved.
The plasma level of adiponectin is decreased in obese individuals ${ }^{30}$ and is closely related to whole-body insulin sensitivity. ${ }^{31}$ A significant decrease in plasma adiponectin is also found in patients with type 2 diabetes. ${ }^{31}$ Adiponectin has been reported to suppress the attachment of monocytes to endothelial cells ${ }^{27}$ and plays a role in the protection against vascular injury, so hypoadiponectinemia is associated with endothelial dysfunction. ${ }^{32}$ Hypoadiponectinemia also seems to cause platelet activation. The level of $\mathrm{NO}$, which regulates platelet activation, is decreased by hypoadiponectinemia because adiponectin stimulates NO production by vascular endothelial cells. ${ }^{33-35}$ Thus, platelet activation occurs due to low NO concentrations in persons with hypoadiponectemia. Therefore, the increase in adiponectin by miglitol may have an antiplatelet effect via the promotion of $\mathrm{NO}$ production. Recently, it has been shown that various posttranslational modifications, including glycosylation of lysine residues, are necessary for the multimerization of adiponectin to occur. ${ }^{36}$ Such intracellular post-translational processes may be affected by hyperglycemia, leading to functional impairment at the organ level in diabetic patients. ${ }^{37-39}$ Therefore, the improvement in postprandial hyperglycemia 
by miglitol could alter the post-translational modification of adiponectin.

In the present study, we found that miglitol caused the reduction of sP-selectin, sE-selectin, and sL-selectin. When the patients in the diabetes group were divided into two subgroups according to the adiponectin response to miglitol treatment, a significant decrease in plasma levels of selectins were found after miglitol treatment in the adiponectin responder group. In addition, similar results were also found for plasma PDMP and sCD40L. These results suggest that miglitol causes adiponectin-dependent improvement in the plasma levels of selectins, PDMP, and sCD40L in diabetic patients.

The exact mechanism by which miglitol treatment leads to an increase in circulating adiponectin levels remains unclear. We postulate the participation of the gut-derived incretin hormone, glucagon-like peptide 1 (GLP-1), for the mechanism underlying adiponectin elevation by miglitol treatment. Recently, the glucose-lowering and anti-obesity effects of GLP-1-based therapies for type 2 diabetes have been extensively evaluated. ${ }^{40}$ One of the antidiabetic effects of miglitol depends on GLP-1, because miglitol can enhance active GLP-1 secretion. ${ }^{28}$ In addition, some studies show that GLP-1 could promote adiponectin secretion. ${ }^{41,42}$ We believe that the effect of miglitol on selectins and platelet activation marker activity depends on adiponectin. Therefore, miglitol could inhibit the progression of atherothrombosis by promoting adiponectin-dependent improvement of the plasma selectins, PDMP, and sCD40L. However, further studies are necessary to elucidate the effects of miglitol itself on adiponectin production.

In conclusion, miglitol increased circulating adiponectin levels in patients with type 2 diabetes. In addition, miglitol treatment led to a decrease in platelet activation markers and selectins. Miglitol may be beneficial for primary prevention of atherothrombosis in patients with type 2 diabetes. However, a large clinical trial to test this hypothesis is required.

\section{Acknowledgments}

This study was partly supported by a grant from the Japan Foundation of Neuropsychiatry and Hematology Research, a Research Grant for Advanced Medical Care from the Ministry of Health and Welfare of Japan, and a Grant (13670760 to SN) from the Ministry of Education, Science and Culture of Japan.

\section{Disclosure}

The authors report no conflicts of interest in this work.

\section{References}

1. Schafer AI. The hypercoagulable states. Ann Intern Med. 1985;102: 814-818.

2. Frade LJG, de la Calle H, Alava I, et al. Diabetes as a hypercoagulable state: its relationship with fibrin fragments and vascular damage. Thromb Res. 1987;47:533-540.

3. Nomura S, Ozaki Y, Ikeda Y. Function and role of microparticles in various clinical settings. Thromb Res. 2008;123:8-23.

4. Cominacini L, Pasini AF, Garbin U, et al. Elevated levels of soluble E-selectin in patients with IDDM and NIDDM: relation to metabolic control. Diabetologia. 1995;38:1122-1124.

5. Lim YC, Snapp K, Kansas GS, et al. Important contributions of P-selectin glycoprotein ligand-1-mediated secondary capture to human monocyte adhesion to P-selectin, E-selectin, and TNF- $\alpha$-activated endothelium under flow in vitro. J Immunol. 1998;161:2501-2508.

6. Tschope D, Esser J, Schwippert B, et al. Large platelets circulate in an activated state in diabetes. Semin Thromb Haemost. $1991 ; 17: 433-439$.

7. Nomura S, Shouzu A, Omoto S, et al. Significance of chemokines and activated platelets in patients with diabetes. Clin Exp Immunol. 2000;121:437-443.

8. Rodriguez BL, Lau N, Burchfiel CM, et al. Glucose intolerance and 23-year risk of coronary heart disease and total mortality: the Honolulu Heart Program. Diabetes Care. 1999;22:1262-1265.

9. Coutinho M, Gerstein HC, Wang Y, et al. The relationship between glucose and incident cardiovascular events. A metaregression analysis of published data from 20 studies of 95,783 individuals followed for 12.4 years. Diabetes Care. 1999;22:233-240.

10. The DECODE study group on behalf of the Europearn Diabetes Epidemiology Group. Glucose tolerance and mortality: comparison of WHO and American Diabetic Association diagnostic criteria. Diabetes Epidemiology: collaborative analysis of diagnostic criteria in Europe. Lancet. 1999;354:617-621.

11. Nakagami T. Hyperglycaemia and mortality from all cause and from cardiovascular disease in five populations of Asian origin. Diabetologia. 2004;47:385-394

12. Chiasson JL, Josse RG, Gomis R, et al. Acarbose for prevention of type 2 diabetes mellitus: the STOP-NIDDM randomized trial. Lancet. 2002;359:2072-2077.

13. Chiasson JL, Josse RG, Gomis R, et al. Acarbose treatment and the risk of cardiovascular disease and hypertension in patients with impaired glucose tolerance: the STOP-NIDDM trial. JAMA. 2003;290:486-494.

14. Hanefield M, Chiasson JL, Koehler C, et al. Acarbose slows progression of intima-media thickness of the carotid arteries in subjects with impaired glucose tolerance. Stroke. 2004;35:1073-1078.

15. Hanefeld M, Cagatay M, Petrowitsch T, et al. Acarbose reduces the risk for myocardial infarction in type 2 diabetic patients: meta-analysis of seven long-term studies. Eur Heart J. 2004;25:10-16.

16. Ahr HJ, Boberg M, Brendel E, Krause HP, Steinke W. Pharmacokinetics of miglitol. Absorption, distribution, metabolism, and excretion following administration to rats, dogs, and man. Arzneimittelforschung. 1997;47:734-745.

17. Osumi K, Ozeki Y, Saito S, et al. Development and assessment of enzyme immunoassay for platelet-derived microparticles. Thromb Haemost. 2001;85:326-330.

18. Nomura S, Uehata S, Saito S. Enzyme immunoassay detection of platelet-derived microparticles and RANTES in acute coronary syndrome. Thromb Haemost. 2003;89:506-512.

19. Nomura S, Shouzu A, Taomoto K, et al. Assessment of an ELISA kit for platelet-derived microparticles by joint research at many institutes I Japan. J Atheroscler Thromb. 2009;16:878-887.

20. Sims PJ, Faioni EM, Wiedmer T, et al. Complement proteins C5b-9 cause release of membrane vesicles from the platelet surface that are enriched in the membrane receptor for coagulation factor Va and express prothrombinase activity. J Biol Chem. 1988;263:18205-18212. 
21. Nomura S, Suzuki M, Katsura K, et al. Platelet-derived microparticles may influence the development of atherosclerosis in diabetes mellitus. Atherosclerosis. 1995;116:235-240.

22. Nomura S, Tandon NN, Nakamura T, et al. High-shear-stress- induced activation of platelets and microparticles enhances expression of cell adhesion molecules in THP-1 and endothelial cells. Atherosclerosis. 2001;158:277-287.

23. Nomura S, Shouzu A, Omoto S, et al. Effect of cilostazol on soluble adhesion molecules and platelet-derived microparticles in patients with diabetes. Thromb Haemost. 1998;80:388-392.

24. Nomura S, Inami N, Iwasaka T, et al. Platelet activation markers, microparticles and soluble adhesion molecules are elevated in patients with arteriosclerosis obliterans: therapeutic effects by cilostazol and potentiation by dipyridamole. Platelets. 2004;15:167-172.

25. Nomura S, Takahashi N, Inami N, et al. Probucol and ticlopidine: effect on platelet and monocyte activation markers in hyperlipidemic patients with and without type 2 diabetes. Atherosclerosis. 2004;174:329-335.

26. Kurowska EM. Nitric oxide therapies in vascular diseases. Curr Pharm Des. 2002;8:155-166.

27. Ouchi N, Kihara S, Arita Y, et al. Novel modulator for endothelial adhesion molecules: adipocyte-derived plasma protein, adiponectin. Circulation. 1999;100:2473-2476.

28. Arakawa M, Ebato C, Mita T, et al. Miglitol suppresses the postprandial increase in interleukin 6 and enhances active glucagons-like peptide secretion in viscerally obese subjects. Metabolism Clin Exp. 2008;57:1299-1306.

29. Yokoyama H, Kanno S, Ishimura I, Node K. Miglitol increases adiponectin level and decreases urinary albumin excretion in patients with type 2 diabetes mellitus. Metabolism Clin Exp. 2008;56:1458-1463.

30. Ouchi N, Kihara S, Arita Y, et al. Adiponectin, an adipocyte-derived plasma protein, inhibits endothelial NF-kappa B signaling through a cAMP-dependent pathway. Circulation. 2000;102:1296-1301.

31. Hotta K, Funahashi T, Arita Y, et al. Plasma concentrations of a novel, adipose-specific protein, adiponectin, in type 2 diabetes patients. Artherioscler Thromb Vasc Biol. 2000;20:1595-1599.
32. Shimabukuro M, Higa N, Asahi T, et al. Hypoadiponectinemia is closely linked to endothelial dysfunction in man. J Clin Endocrinol Metab. 2003;88:3236-3240.

33. Chen H, Montagnani M, Funahashi T, et al. Adiponectin stimulates production of nitric oxide in vascular endothelial cells. J Biol Chem. 2003;278:45021-45026.

34. Hattori Y, Suzuki M, Hattori S, et al. Globular adiponectin upregulates nitric oxide production in vascular endothelial cells. Diabetologia. 2003;46:1543-1549.

35. Nomura S, Shouzu A, Omoto S, et al. Correlation between adiponectin and reduction of cell adhesion molecules after pitavastatin treatment in hyperlipidemic patients with type 2 diabetes mellitus. Thromb Res. 2008; 122:39-45.

36. Wang Y, Lam KS, Chan L, et al. Post-translational modifications of the four conserved lysine residues within the collagenous domain of adiponectin are required for the formation of its high molecular weight oligomeric complex. J Biol Chem. 2006;281:16391-16400.

37. Fülöp N, Marchase RB, Chatham JC. Role of protein O-linked $\mathrm{N}$-acetyl-glucosamine in mediating cell function and survival in the cardiovascular system. Cardiovasc Res. 2007;73:288-297.

38. Fülöp N, Mason MM, Dutta K, et al. Impact of Type 2 diabetes and aging on cardiomyocyte function and $\mathrm{O}$-linked $\mathrm{N}$-acetylglucosamine levels in the heart. Am J Physiol Cell Physiol. 2007;292:C1370-C1378.

39. Ochiai H, Ooka H, Shida C, et al. Acarbose treatment increases serum total adiponectin levels in patients with type 2 diabetes. Endocr $J$. 2008;55:549-556.

40. Knop FK, Vilsboll T, Larsen S, Madsbad S, Holst JJ, Krarup T. No hypoglycemia after subcutaneous administration of glucagons-like peptide-1 in lean type 2 diabetic patients and in patients with diabetes secondary to chronic pancreatitis. Diabetes Care. 2003;26:2581-2587.

41. Pocai A, Carrington PE, Adams JR, et al. Glucagon-like peptide 1/ glucagons receptor dual agonism reverses obesity in mice. Diabetes. 2009;58:2258-2266.

42. KimVhung le T, Hosaka T, Yoshida M, et al. Exendin-4, a GLP-1 receptor agonist, directly induces adiponectin expression through protein kinase A pathway and prevents inflammatory adipokine expression. Biochem Biophys Res Commun. 2009;390:613-618.
International Journal of General Medicine

\section{Publish your work in this journal}

The International Journal of General Medicine is an international, peer-reviewed open-access journal that focuses on general and internal medicine, pathogenesis, epidemiology, diagnosis, monitoring and treatment protocols. The journal is characterized by the rapid reporting of reviews, original research and clinical studies across all disease areas.

\section{Dovepress}

A key focus is the elucidation of disease processes and management protocols resulting in improved outcomes for the patient.The manuscript management system is completely online and includes a very quick and fair peer-review system. Visit http://www.dovepress.com/ testimonials.php to read real quotes from published authors. 